\title{
Crocus test results for snowpack modeling in two snow climates with respect to avalanche forecasting
}

\author{
Laurent Mingo, ${ }^{1}$ D. M. McGlung ${ }^{2}$ \\ ${ }^{1}$ Alpine Science Consulting and Engineering, 681 West 23rd Avenue, Vancouver, British Columbia V5Z 2A5, Canada \\ ${ }^{2}$ Department of Geography, University of British Columbia, Vancouver, British Columbia V61 1Z2, Canada
}

\begin{abstract}
Overall results comparing field observations and Crocus simulations during the winters 1993-94 and 1994-95 in two different climate zones are presented. We present information on: snow depth, snow-temperature profiles, density profiles, liquidwater content profiles and grain metamorphism. Snow profiles illustrating the typical behavior of the model are presented and are shown to illustrate the sensitivity of Crocus to different mountain climates. Heat-exchange simulation, together with qualitative analysis of meteorological data, give promising results for surface-hoar prediction.
\end{abstract}

\section{INTRODUCTION}

Within the last decade, snow and avalanche research has been marked by a significant increase in the use of computer models to simulate snowpack characteristics and assess avalanche hazard on a meso-scale. Growing availability of various sources of meteorological data has played an important role in the method used in these models. Initially, air temperature and precipitation were the main parameters used in numerous snow models which had their "time-of-glory", especially for the hydrologist. However, they were not adapted for deriving snowpack parameters and their internal characteristics. More recently, deterministic snowpack models have been introduced to model avalanche phenomena. Together with statistical models and expert systems, they form a highly developed set of analytical tools.

As described by McClung and Schaerer (1993), data to interpret snow stability and for avalanche-hazard assessment can be grouped in three classes based on relevance and ease of interpretation. Class I contains the stability factors which are the most relevant for the task, while snowpack data form class II. This type of information is obtained by performing a full snow profile and can only be done at isolated spots. Local stability can then be derived from analysis of the snowpack data. Extension to the larger scale remains the task of the avalanche expert taking into consideration knowledge of the terrain, experience and intuition. Finally, class III contains meteorological and snowfall data. These data are characterized by both much wider scale and easier availability than class I and II data but are significantly less informative with regard to the snowpack and its stability. Meso-scale evaluation of the avalanche hazard (refering to class I factors) is both time-consuming and subject to difficulties of accessing the terrain. Mesoscale analysis can be aided by using meteorological data. Two independent tasks must be accomplished to obtain a reasonable avalanche-hazard assessment. The first is to provide a meaningful set of snowpack parameters derived from meteorological data and the second is to assist the reasoning of the expert with all his/her "bag-of-tricks" (rules of deci- sion used by experienced avalanche forecasters) to assess the hazard. Expert systems (Giraud, 1993; McClung, 1995a; Schweizer and Föhn, 1996) are becoming the norm for this second task. As far as the first task is concerned, the Crocus model (Brun and others, 1989, 1992) seems to be the most advanced technique to date for deterministic snowpack modeling.

This paper presents complete results of a field testing of Crocus carried out in two distinct zones (Armstrong and Armstrong, 1987). It explores the performance of the model in climatic zones significantly different from previously published work (Brun and others, 1989, 1992). Analysis is also performed with respect to use of the model for operational avalanche-hazard assessment with emphasis on the key parameters avalanche experts need for stability and avalanche-hazard evaluation.

\section{CROCUS AND RELEVANT INTERNAL SNOWPACK PARAMETERS FOR STABILITY EVALUATION AND AVALANCHE FORECASTING}

\section{Snowpack internal parameters}

Except for snow temperature, the following internal snowpack parameters, generally used to locate the presence of weak layers, indicate the presence of slab structures in the snowpack as well as their relative position and weaknesses throughout the layering.

\section{Hardness}

Hardness is often the first parameter forecasters look at. It is essential for extracting the slab structure of the snowpack as well as for locating weak layers. Generally speaking, it can be considered as a good indicator of shear strength, although it is only an index property of it. Unfortunately, hardness-governing laws, and more ideally shear strength, remain quite difficult to model and a physically based approach has not yet been proposed. Brun and Rey (1987) did some work in this direction and the expert system MÉPRA (Giraud, 1993) uses empirical relations (not available 
at the time of this study) to derive shear strength. These relations represent a crucial link between Crocus and MÉPRA and deserve broader description.

\section{Grain type}

Grain type is another very significant parameter for determining the presence of weak layers and potential layers for fracture propagation. Three types are particularly important for forecasters in relation to skiing accidents (Jamieson and Johnston, 1992): depth hoar, faceted grains and surface hoar.

It is critical to establish whether these forms are well simulated by the model. Surface-hoar growth takes place at the snow surface and is also a direct consequence of the micrometeorology prevailing at the snow surface. In mountainous terrain, current micrometeorological monitoring systems may not enable accurate simulation of surface hoar. Although surface hoar is not predicted in the version of $\mathrm{Cro}$ cus used for this test, we attempted to recognize surface-hoar growth periods using heat-exchange simulation at the surface of the snow cover. Crusts, resulting from refreezing after rain or solar radiation need to be located because faceted grains often occur above or below them. Hard crusts can also be a barrier to percolating water and once lubricated, represent a major slide plane for an overlying slab.

\section{Grain bonds}

Bonding quantification is very difficult to obtain without direct field testing. Roughly speaking, temperatures and grain types can help give an approximate idea of grain bonding both within and between layers. Nevertheless, no deterministic approach is yet available for modeling bonding.

\section{Temperature and temperature gradient}

Temperature profiles are highly significant because snow temperature controls the type and magnitude of metamorphism. Grain bonding also depends on snow temperature. As slab-avalanche release depends on snow temperature (McClung, 1995b), a good simulation of this parameter is critical.

\section{Density}

Density is also significant, because it indicates weak layers as well as grain compaction, which can be very useful for estimating bond formation.

\section{Liquid-water content}

Wet snow tends to be weak so strength decreases with the amount of liquid-water content. However, since most of the profiles in this work were in dry snow, comparison here is somewhat limited.

\section{Parameters returned by Crocus}

Air temperature, wind speed, relative humidity, incoming shortwave and longwave radiation, new snow, new-snow density, rain and soil thermal flux have to be supplied to the model hourly. If there is already snow on the ground, a snow profile provides the initial conditions. After simulation, Crocus returns a layered snowpack, with temperature, density, grain-size and type and liquid-water content for each layer. Total snow depth and bottom-water run-off are also computed. The underlying equations have been described by Brun and others $(1989,1992)$. As far as a physically based approach is concerned, the above parameters are all that can be provided to date.

Hardness and grain bonding will have to be derived through empirical-statistical or expert approaches so that class II parameters can be successfully simulated. Only then, will analysis systems for stability appraisal based on field snowpack parameters become meaningful for simulated snow profiles. In this way, one might expect to improve the model's ability to derive snowpack stability from meteorological data.

\section{THE TEST SITES}

\section{Mount Fidelity, Rogers Pass, Selkirk Mountains}

The site is lies at $1910 \mathrm{~m}$ a.s.l. near tree line in the western part of Glacier National Park, in eastern British Columbia, Canada. The study plot is flat and part of a wide east-facing ridge. This area is characterized by a transitional snow climate between maritime and continental types (McClung and Schaerer, 1993).

\section{Blackcomb Peak, Coast Mountains}

The site lies within the Blackcomb Mountain Ski area, $90 \mathrm{~km}$ north of Vancouver, in western British Columbia. Situated on a wide shoulder at $1860 \mathrm{~m}$ a.s.l., it overlooks the valley bottom and has a north-northwest aspect on nearly
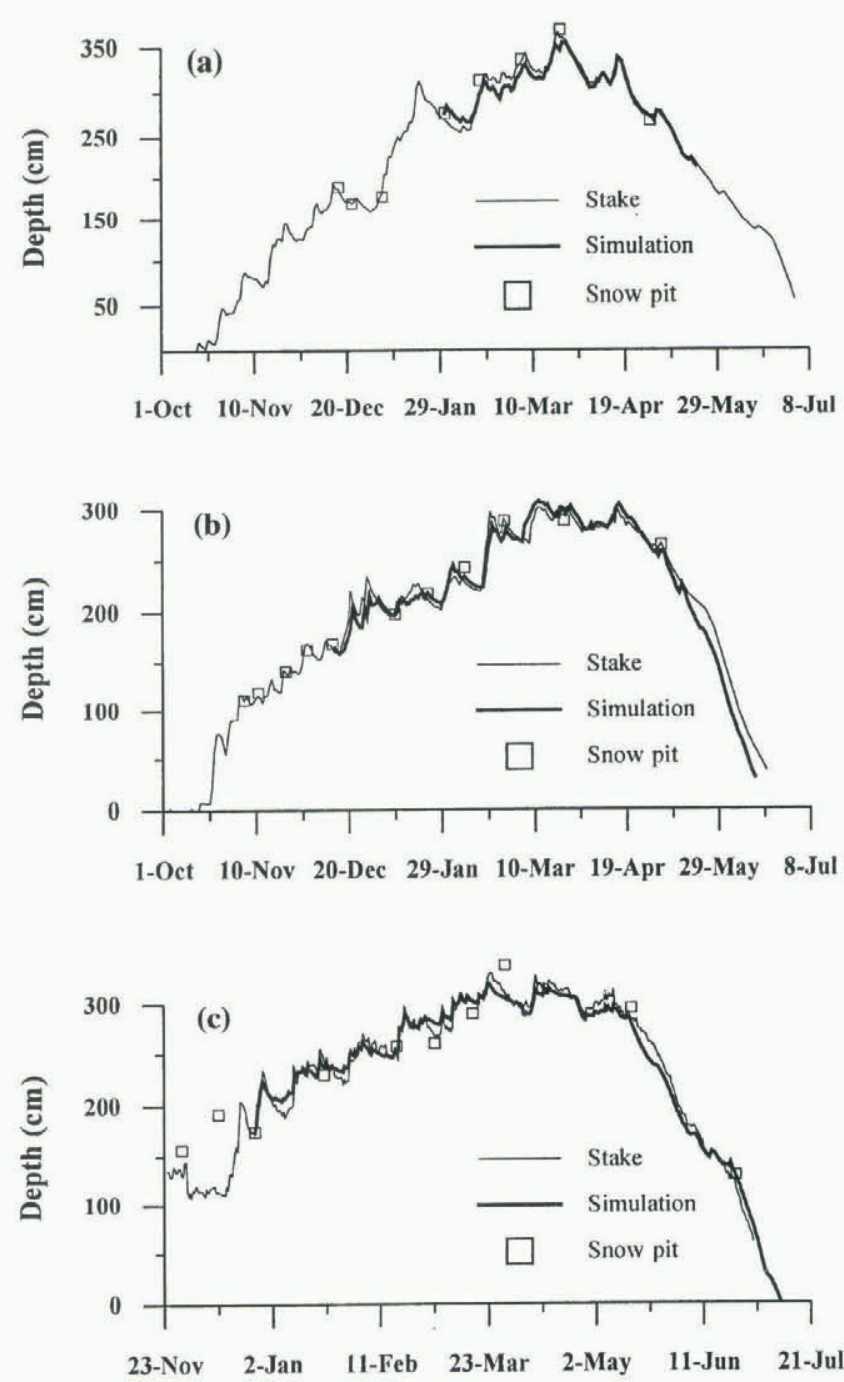

Fig. 1. Snow depth. (a) Mount Fidelity, winter 1993-94. (b) Mount Fidelity, winter 1994-95. (c) Blackcomb Peak, winter 1994-95. 

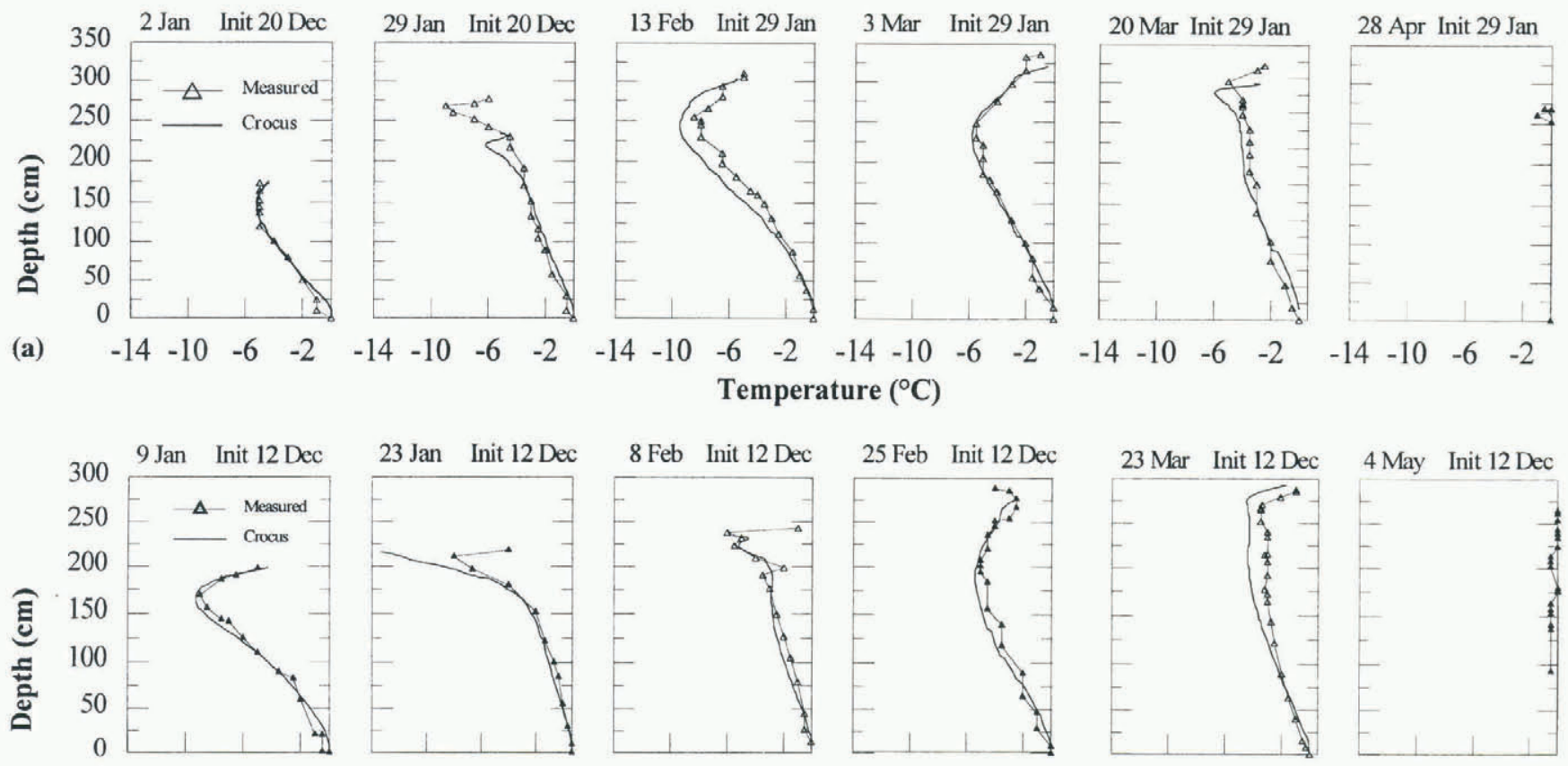

(b)
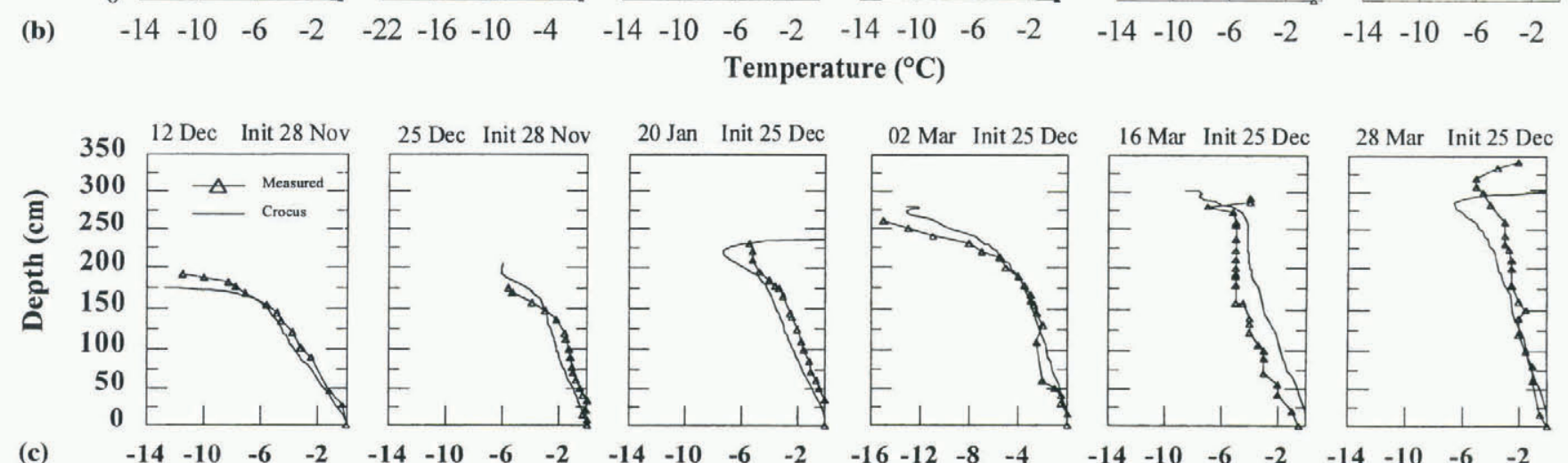

Temperature $\left({ }^{\circ} \mathrm{C}\right)$

Fig. 2. Comparison of observed temperature profile and simulation. (a) Mount Fidelity, winter 1993-94. (b) Mount Fidelity, winter 1994 -95. (c) Mount Fidelity for the winter 1994-95.

flat terrain. The snow climate is typically maritime with mild temperatures and deep snowpacks.

\section{INSTRUMENTATION}

Model input data were acquired in 1993-94 and 1994-95 at Mount Fidelity and 1994-95 at Blackcomb Peak. Meteorological data were measured automatically, except for the new-snow density and ground heat flux. For Blackcomb, new-snow density was derived from wind and temperature according to Pahaut (1975) and Meister (1985). A combination of new-snow and water-equivalent readings was used to derive new-snow density for Mount Fidelity. In both cases, ground heat flux was estimated. Solar and infrared radiation were measured at both sites with Eppley radiometers. For infrared radiation measurement, over heating of the dome of the pyrgeometer was corrected according to Alados-Arboedas and others (1988). The principal problem with these instruments was they could be buried during snowfalls. However, daily manned presence at the study plot by Glacier National Park's avalanche control staff (Mount Fidelity) and Blackcomb ski patrol (Blackcomb Peak) significantly reduced this problem.

\section{SNOW DEPTH}

During winter 1993-94 tests were conducted at Mount Fidelity. Crocus was initialized on 29 January 1994 and was run until mid-May. Excellent performance during accumulation, settlement and melting periods is illustrated in Figure la. The following winter, the model was initialized on 12 December 1994. No re-initialization was applied during the next 6 months and excellent agreement between both observed and simulated snow depths is demonstrated (Fig. lb). Figure lc shows results for Blackcomb Peak (winter 1994-95). At both sites, simulation yielded very good results.

\section{TEMPERATURE, DENSITY AND LIQUID-WATER CONTENT PROFILES}

Figure 2a, b and c show measured and simulated temperature profiles at Mount Fidelity and Blackcomb Peak. Excellent agreement is shown. Cold as well as warm snowpacks are correctly simulated. A few mismatches can be observed for freshly fallen snow or at the top of the snow cover. Since air temperature is used to set the fresh-snow temperature when it reaches the surface of the snow cover, 
it takes a few time-steps for the simulated temperature to evolve according to surface heat exchanges. Some near-surface discrepancies may be due to partial burial of radiometers between daily visits to the study plot. This probably happened in isolated cases over the 600 test days. Good simulation of temperature profiles reveals that heat exchanges are correctly modeled. Since temperature gradients were successfully reproduced, a necessary condition for grain-metamorphism simulation is achieved. It must be noted, however, that the field study did not focus on the temperature gradients in the first top millimeters of the snow pack, another very important source of weak-layer formation. Birkeland and others (1997) have shown the high significance of near-surface faceting, including radiation crystallization, as a weak layer. Extreme accuracy must be achieved to model this phenomenon.

After calculation of temperature profiles, phase changes are computed. Settlement is taken into account by decreasing the thickness of each layer and a new density is derived (Brun and others, 1989). The density simulations shown in Figure $3 \mathrm{a}$ and $\mathrm{b}$ depict very good results. Density drops in the Mount Fidelity simulation curves (for instance, around $225 \mathrm{~cm}$ for 3 and 20 March in Figure 3a) are due to buried thin layers of surface hoar (observed in the field profile). They were entered into the model (initialization profile) with a low density. For such thin layers, density is usually not measured and this explains why no corresponding sharp drops are found in the experimental density curves. For the profile of 28 April 1994 (Mount Fidelity), the low surface density returned by the model was a thin layer of new snow which prevented density measurements. This explains the mismatch that appears at the top of the profile. Blackcomb's density profiles (Fig. 3c), are not as good as those on Mount Fidelity. Frequent gusty wind conditions are likely to be the origin of mismatches. New-snow density was derived from wind and temperature data using Pahaut's equation, although it is restricted to winds not exceeding $5 \mathrm{~m} \mathrm{~s}^{-1}$. An upper limit of $130 \mathrm{~kg} \mathrm{~m}^{-3}$ (Meister, 1985) was chosen for Blackcomb when the strongest winds prevailed. The lack of manual density data is certainly a source of error to take into account for operational use of the model at a larger scale where such data are not available. Furthermore, snow is redistributed after a storm during windy conditions. As a result, the actual density might have increased due to windpacking, leading to erratic simulations.

Liquid-water content profiles are shown in Figure 4. Considering that Crocus is a one-dimensional model (no account being taken of percolation) and that the assumption of total meltwater absorption by the ground may not hold at all times, the results are of good quality.
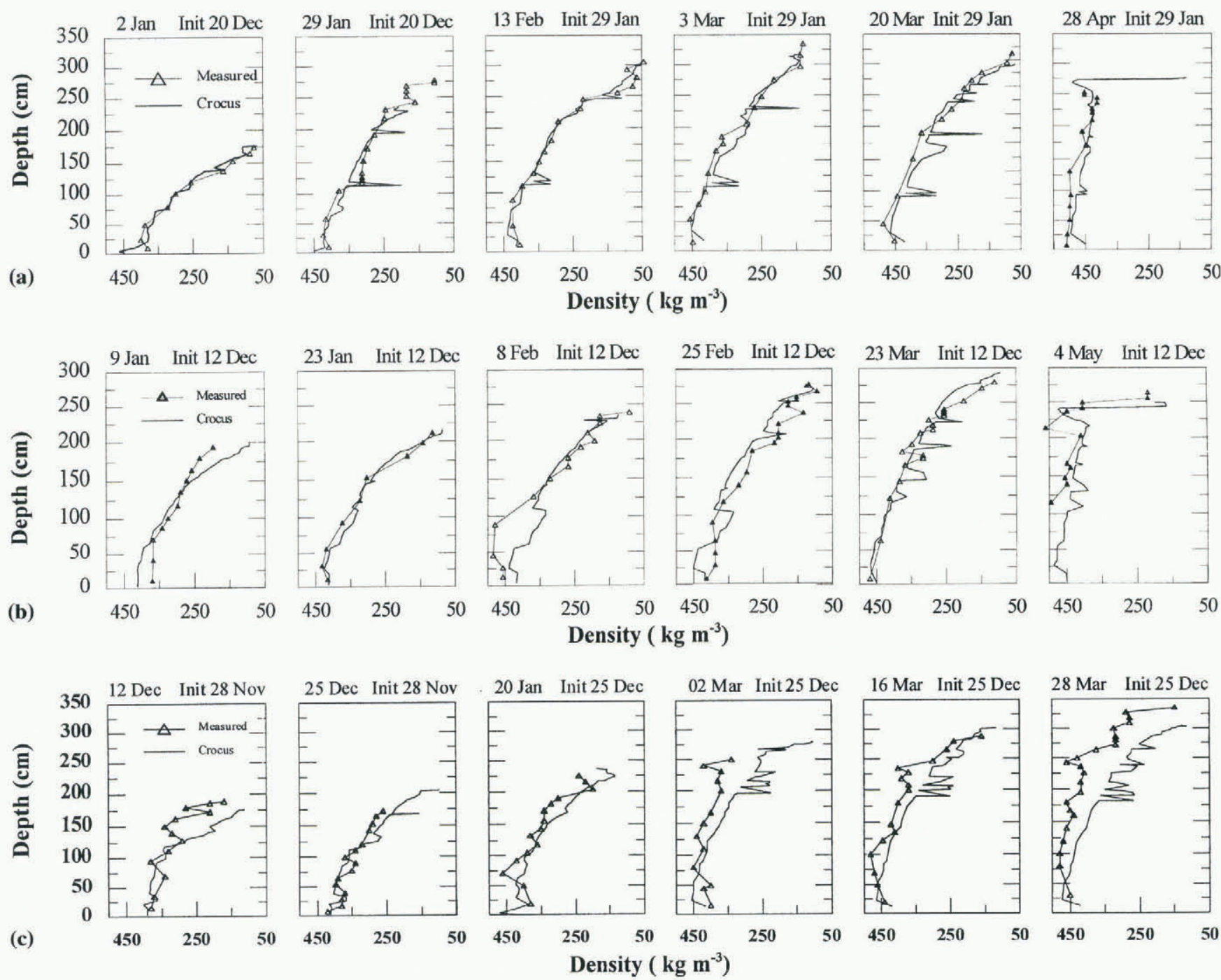

Fig. 3. Comparison of observed density profile and simulation. (a) Mount Fidelity, winter 1993-94. (b) Mount Fidelity, winter 1994-95. (c) Blackcomb Peak, winter 1994-95. 

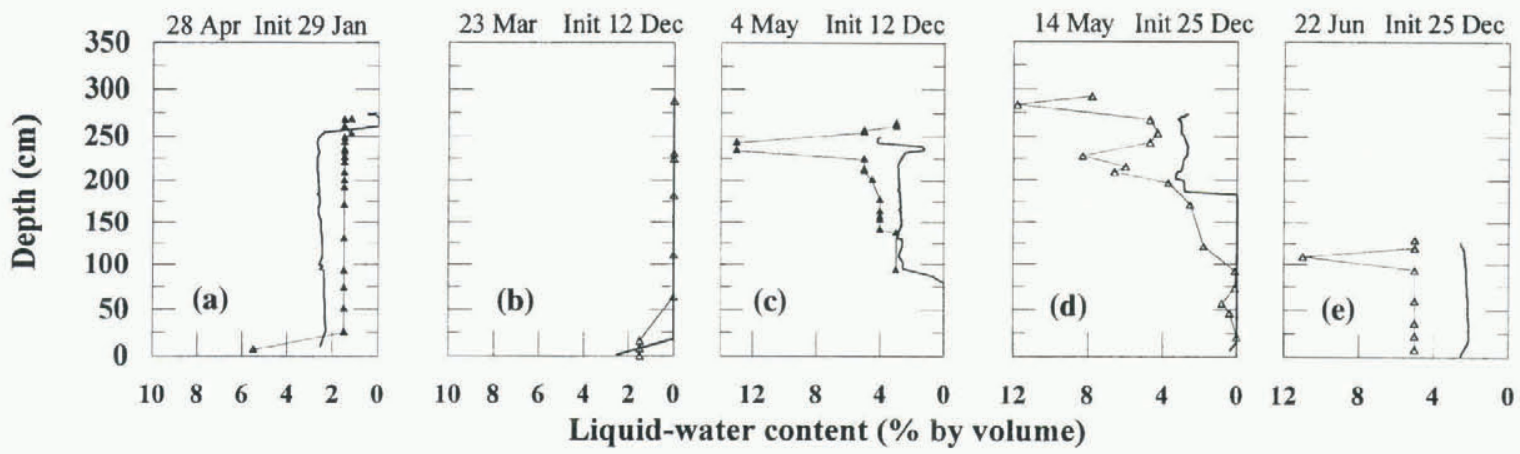

Fig. 4. Comparison of estimated liquid-water content profiles and simulation. (a) Mount Fidelity, winter 1993-94. (b and c) Mount Fidelity, winter 1994-95. (d and e) Blackcomb Peak, winter 1994-95.

\section{GRAIN METAMORPHISM}

\section{Quantification of snow-metamorphism laws}

Snow metamorphism potentially affects most of the properties of the snowpack. In particular, mechanical properties and albedo are highly dependent on grain type. Based on previous work and experiments, Brun and others (1992) derived metamorphism laws for dry and wet snow as functions of temperature, temperature gradient, density, grain-size, water content and time. To include grain metamorphism in the model, Brun and others (1992) introduced continuous parameters to describe grain forms, resulting in the concepts of dendricity and sphericity (with indices between 0 and 99 or 0 and 1 depending on the adopted convention).

Dendricity quantifies how much of their initial shape the crystals still retain.

Sphericity describes the degree of spherical shape.

When dendricity reaches 0 , a faceted grain is described, (a)

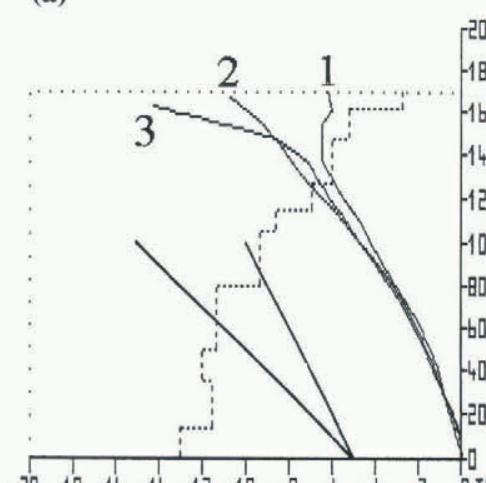

1

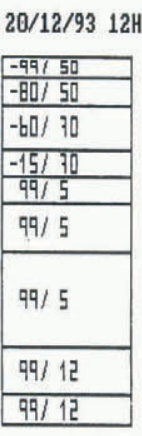

2

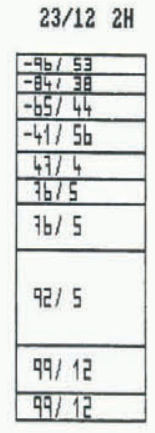

3

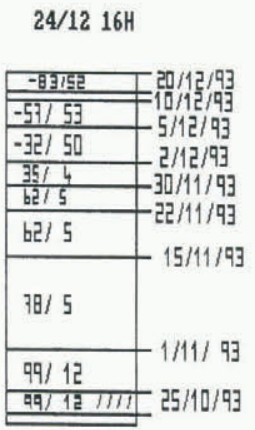

(b)

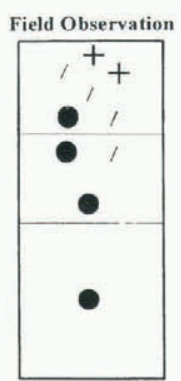

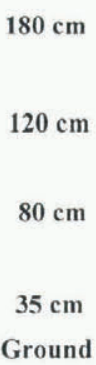

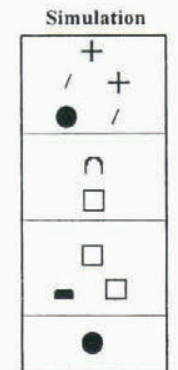

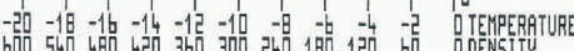

4

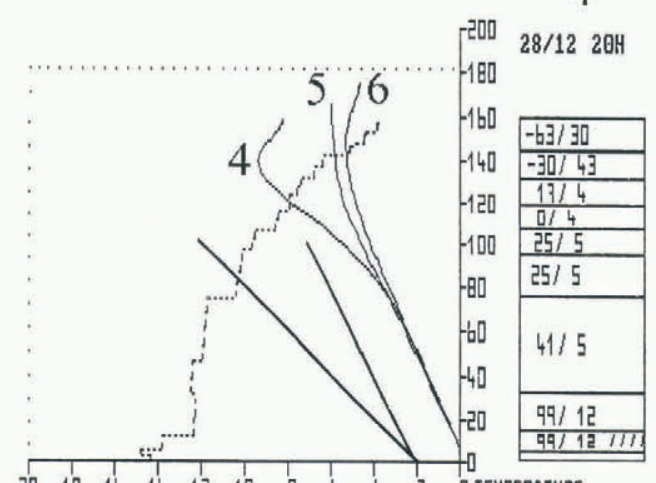

5

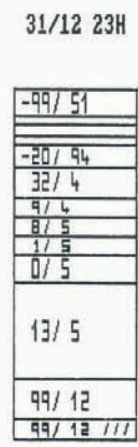

6

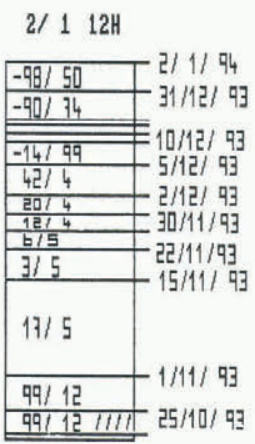

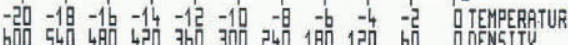

Fig. 5. (a) Simulation of temperature profiles and grain metamorphism from 20 December 1993 to 2 January 1994. Profile 1 is the initialization profile. Figure description. Grains are expressed as follow: $A A / B B$ means $A A=$ dendricity and $B B=$ sphericity; $A A / B B$ (no"-") means $A A=$ sphericity and $B B=$ size in $1 / 10 \mathrm{~mm}$. For instance, $-99 / 50$ indicates dendricity $=99$ and sphericity $=50.80 / 5$ or $99 / 5$ indicates rounded grains with sphericity equal respectively to 80 and 99 and grain-size equal to $0.5 \mathrm{~mm} .10 / 6,0 / 6$ is an example of facets where sphericity is low, respectively 10 and 0 , with grain-size equal to $0.6 \mathrm{~mm}$. Beside grain form, temperature profiles are shown and can be compared to the $5^{\circ} \mathrm{Cm}^{-1}$ and $10^{\circ} \mathrm{Cm}^{-1} \mathrm{TG}$ represented by the two straight lines on the graph; numbered curves show the snow temperature. The stepping curve is the density output of the model. The //// in the layering depicts a refrozen layer. The rightmost numbers illustrate the date a given layer formed.

(b) Simplified profiles for 2 January 1994 using the ICSI classification (Colbeck and others, 1990). 
$1-2$

(a)

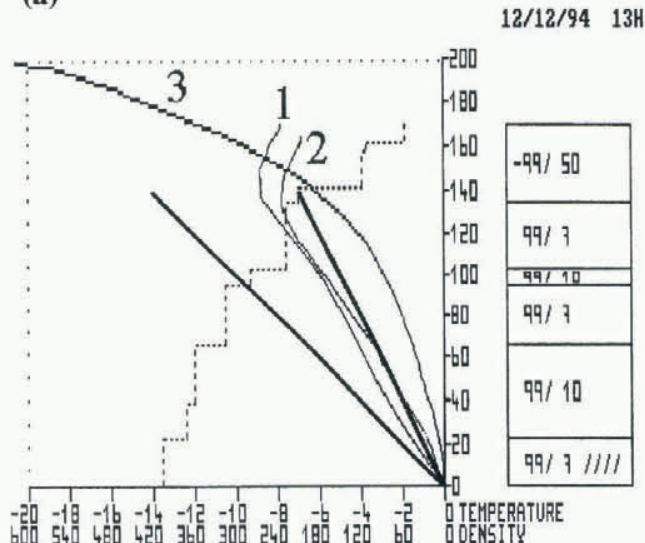

3

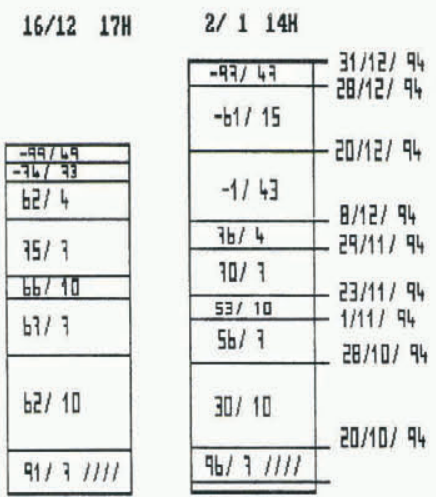

(b)

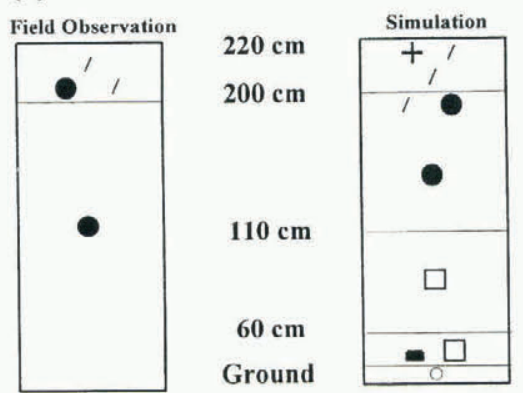

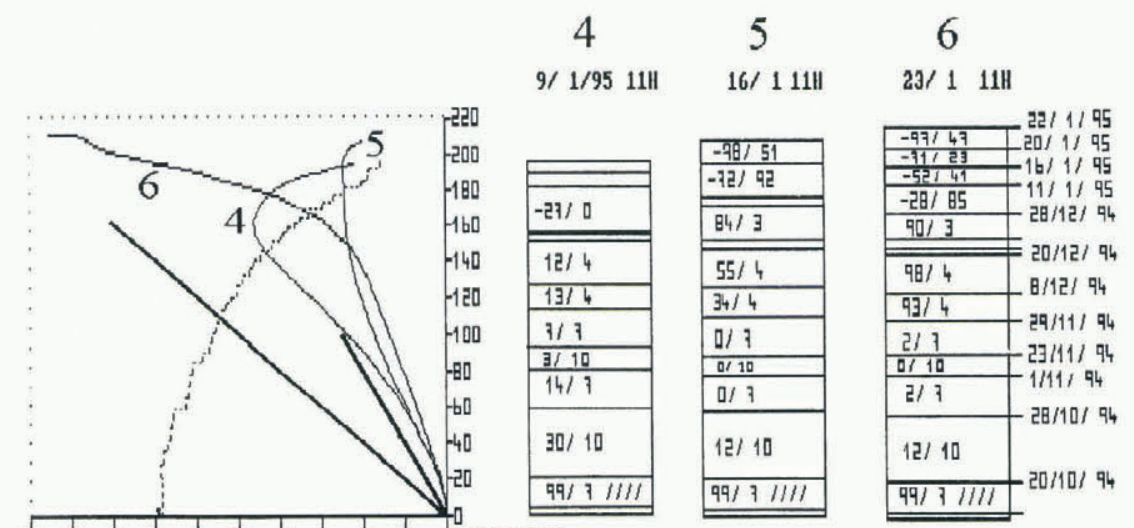

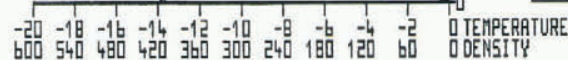

\begin{abstract}
Figure 6. (a) Simulation of temperature profiles and grain metamorphism from 12 December 1994 to 23 January 1995. Profile 1 is the initialization profile. Same description as for Figure 5. (b) Simplified profiles for 23 January 1995 using the ICSI classification (Colbeck and others, 1990).
\end{abstract}

whereas for rounded grains sphericity is 99 . Grain-size is also used to characterize the evolution of facets towards depth hoar and fine rounded grains towards coarse rounded grains. Note that all initial grains are assumed dendritic.

\section{Discrimination of the type of metamorphism}

Proposed discrimination of the type of metamorphism is based on the magnitude of the prevailing temperature gradient within a given layer (Brun and others, 1992). For dry snow, when $|\Delta T / \Delta Z|<5^{\circ} \mathrm{Cm}^{-1}$, a low-gradient metamorphism scheme is used. Dendricity decreases with time and sphericity increases, both at greater rates when temperature increases. Eventually, if the trend continues, rounded grains are simulated. When $|\Delta T / \Delta Z| \geq 5^{\circ} \mathrm{Cm}^{-1}$, a strong gradient-metamorphism scheme is applied. Dendricity still decreases but, unlike in the previous case, sphericity also diminishes. Grains become more angular and can eventually reach a faceted state. Increase of temperature and/or temperature gradient leads to greater rates in the evolution of dendricity and sphericity. Finally, if growth continues, grains evolve to depth hoar. To model wet-snow metamorphism, sphericity and dendricity are controlled by the water content of the layer considered.

\section{Grain-type simulation}

In this section, both satisfactory and unsatisfactory simulations are grouped according to meteorological patterns leading to climatic dependent performances. First, typically https://doi.org/10.3189/1998AoG26-1-347-356 Published online by Cambridge University Press erroneous simulations are shown in the 2 January 1994 and 23 January 1995 profiles (Mount Fidelity). Then, two typically successful simulations are shown in the 8 and 25 February profiles (Mount Fidelity). Figures 5a, 6a, 7a and 8a give direct Crocus outputs, while simplified corresponding simulation profiles are compared with field profiles in Figures $5 b, 6 b, 7 b$ and $8 b$.

\section{Mount Fidelity 1993-94, 2 January initialization 20 December} Simulation plots are presented at regular intervals between 20 December and 2 January in Figure 5a. For each, the temperature profile is shown. In the righthand columns, dendricity/sphericity are given. Here, one can split the snowpack in three parts:

Lower part: between 0 (ground) and $80 \mathrm{~cm}$.

Mid part: between 80 and $140 \mathrm{~cm}$.

Upper part: from $140 \mathrm{~cm}$ to surface.

The upper snowpack is first subjected to a temperature gradient ranging from $5^{\circ} \mathrm{C} \mathrm{m}^{-1}$ to close to $10^{\circ} \mathrm{Cm}^{-1}$ (according to the simulation) during the first few days after 20 December. During this period, a moderately cold period prevailed until 24 December with air temperatures steadily increasing from about $-12^{\circ} \mathrm{C}$ to $-8^{\circ} \mathrm{C}$. Afterward, until 2 January, milder temperatures were observed (close to $-5^{\circ} \mathrm{C}$ ), leading to an upper snowpack nearly isothermal at around $-5^{\circ} \mathrm{C}$ after 28 December. Grain simulation (Figure 5b) is satisfactory here. 
(a)

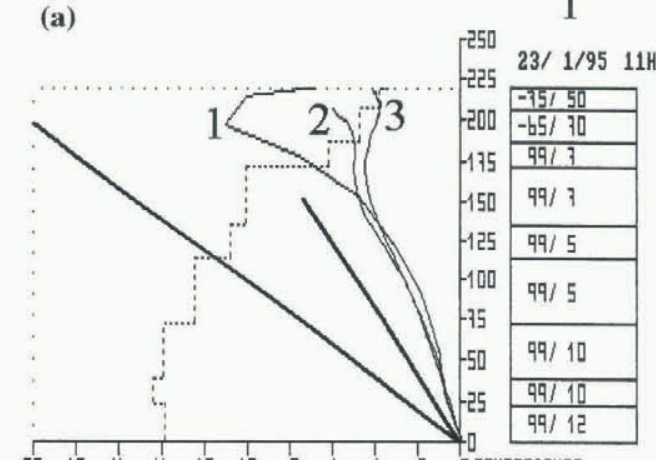

2

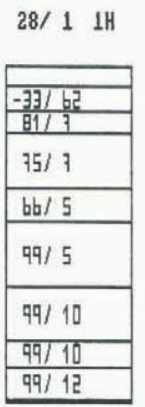

3

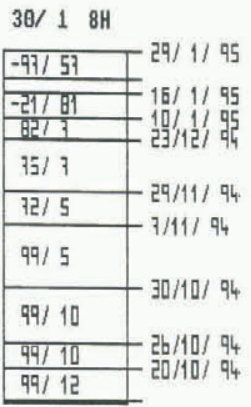

(b)

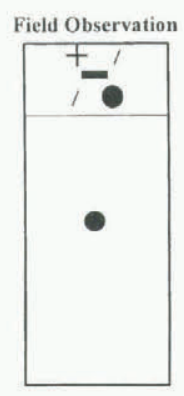

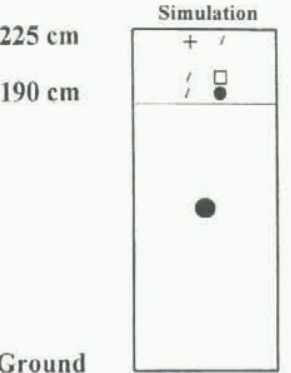

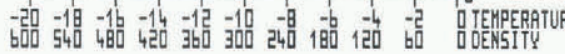
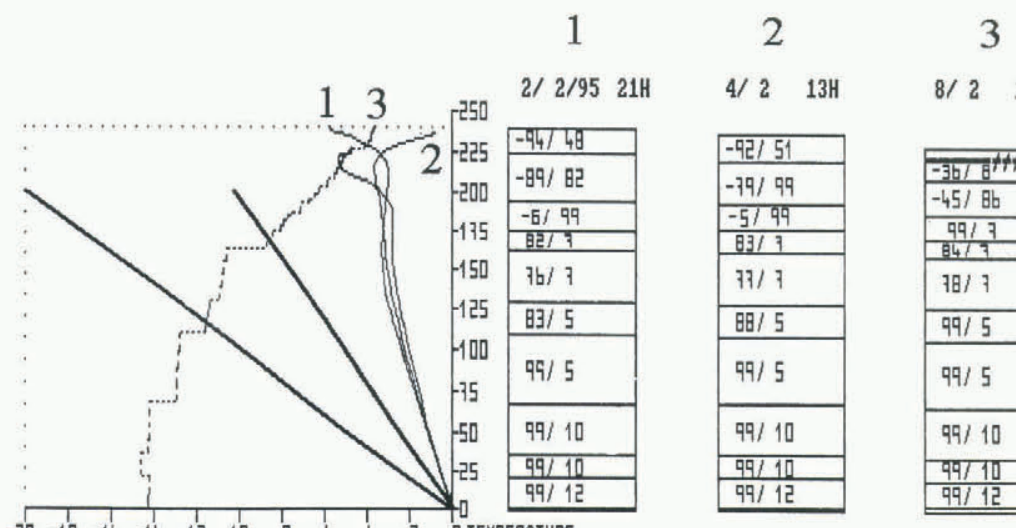

$8 / 212 \mathrm{H}$

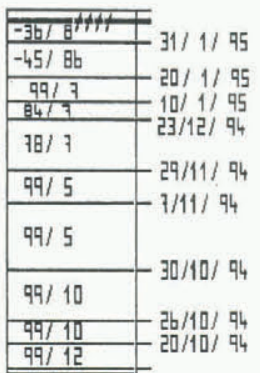

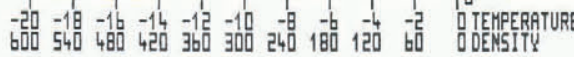

Fig. 7. (a) Simulation of temperature profiles and grain metamorphism from 23 January 1995 to 8 February 1995. 23 January profile is the initialization profile. Same description as for Figure 5. (b) Simplified profiles for 8 February 1995 using the ICSI classification (Colbeck and others, 1990).

In the mid-snowpack, simulated temperature gradients (TGs) reached between $6^{\circ}$ and $8^{\circ} \mathrm{C} \mathrm{m}^{-1}$ from 20 to 24 December and increased to nearly $10^{\circ} \mathrm{C} \mathrm{m}^{-1}$ on 28 December. Simulated grains transformed towards facets with a decreasing sphericity. In particular, a few layers are identified as facets with very low sphericity $(0$ on 28 December, between 0 and 10 on 28 December 28 ) around $100 \mathrm{~cm}$. Afterwards, and until 2 January, weaker TGs $\left(4-5^{\circ} \mathrm{C} \mathrm{m}^{-1}\right)$ allow simulated rounding to occur but not enough to match the field profile reasonably in the mid-snowpack where facets were returned.

The bottom part showed a steady decrease in sphericity, leading to partially faceted grains not confirmed by field observation. Throughout the considered time period, this layer was submitted to a gradient slightly greater than $5^{\circ} \mathrm{C} \mathrm{m}^{-1}$. The underlying layer, down to ground level, never experienced gradients stronger than $5^{\circ} \mathrm{Cm}^{-1}$ and the profile exhibits rounded grains confirmed by field observations.

\section{Mount Fidelity 1994-95, 23 January initialization 12 December}

Until 23 January, the lower snowpack - below $100 \mathrm{~cm}$ in this case - is consistently submitted to a gradient ranging between 4 and $6^{\circ} \mathrm{C} \mathrm{m}^{-1}$ (Fig. 6a). However, steady faceting was simulated until 23 January resulting in a mainly faceted lower snowpack except for the $20 \mathrm{~cm}$ above ground. The layer, formed on 28 October, can be tracked easily, its sphericity decreasing from 99 to 12 with TG slightly greater than $5^{\circ} \mathrm{Cm}^{-1}$. This is in contrast to the observed profiles where only rounded grains were observed (Fig. 6b). If no re-initialization was applied at this point, future profiles would be incorrectly simulated. 8 and 25 February profiles would show such a bias with faceted lower snowpacks, un- less re-initialization was applied on 23 January. Weather conditions would then lead to a satisfactory response of the model as shown below.

\section{Mount Fidelity 1994-95, 8 February initialization 23 January}

During this period, weak TGs characterized the snowpack (Fig. 7a). Rounded grains already present on 23 January, were still found on 8 February. Simulation and observation were in strong agreement as illustrated on Figure $7 \mathrm{~b}$.

\section{Mount Fidelity 1994-95, 25 February initialization 23 January}

Once again, the simulation was initiated with a mainly rounded snowpack on 23 January. Until 8 February, mild weather conditions prevailed, leading to weak TGs and little if any changes in metamorphism. Starting on 9 February, a colder air mass invaded the area and temperatures dropped significantly (down to $-20^{\circ} \mathrm{C}$ ) with clear skies. One would then expect the snowpack to present stronger TGs, at least in the upper part. Simulation clearly showed that trend: strong TGs returned and faceting was simulated (Fig. 8a). The cold spell remained over the region until 15-16 February, and was followed by a milder period until 25 February accompanied by snow precipitation until 21 February. As a result, the 25 February simulation presents an upper snowpack composed of new snow, overlying some rounded grains, and between 160 and $110 \mathrm{~cm}$, mainly faceted grains. Below, older rounded crystals were simulated. Here, field observation agreed with the simulation (Fig. 8b).

\section{Conclusion on grain metamorphism}

A very specific type of meteorological condition associated 


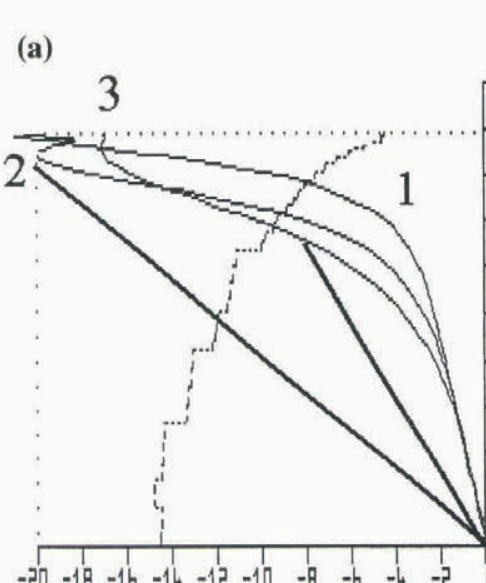

12

3

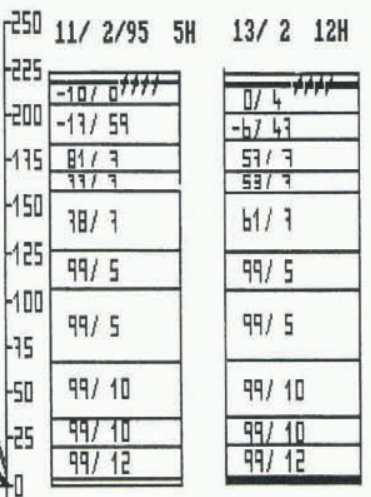

$15 / 29$ H

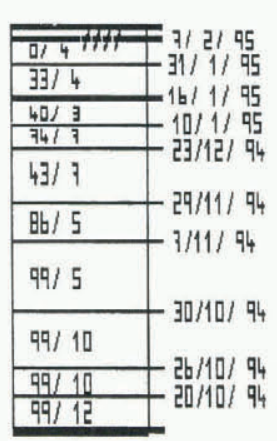

(b)

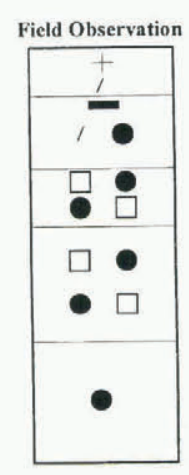

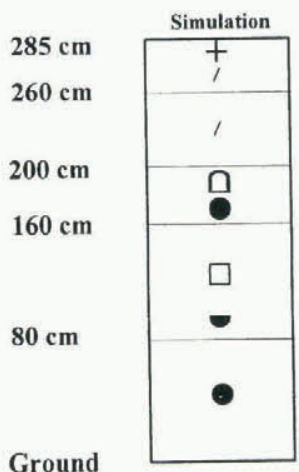

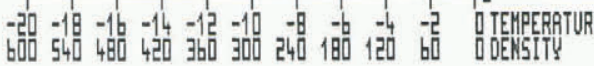
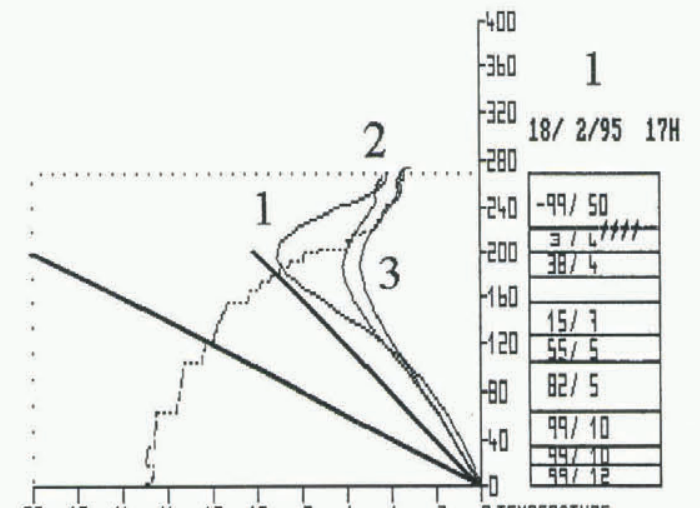

2

$22 / 2$ 21H

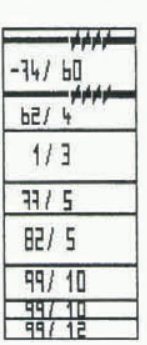

3

$25 / 211 \mathrm{H}$

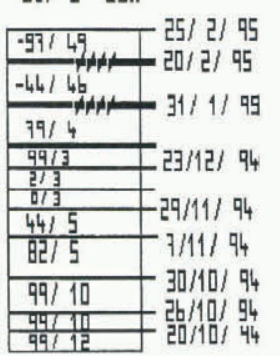

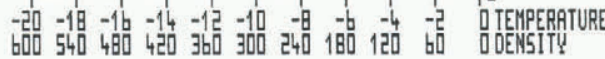

Fig. 8. (a) Simulation of temperature profiles and grain metamorphism from 23 January 1995 to 25 February 1995. Same description as for Figure 5. ( b) Simplified profiles for 25 February 1995 using the ICSI classification (Colbeck and others, 1990).

with snow depth, leading to faulty simulations, has been identified. When TG is slightly greater than $5^{\circ} \mathrm{Cm}^{-1}$, the model creates facets. Field observations do not confirm the formation of faceted grains. On the other hand, when TG is well off the model's threshold (greater than $10^{\circ} \mathrm{C} \mathrm{m}^{-1}$ or close to isothermal), simulations are successful. Examples provided by the Mount Fidelity data show this trend clearly due to the presence of weather conditions where TGs with different magnitudes (weak, near $5^{\circ} \mathrm{Cm}^{-1}$ and strong) occurred. On a profile-to-profile comparison, Blackcomb's profiles do not usually present suchTG variability and simulations were generally good, except at the very top of the snowpack where the same anomaly was also noted (Mingo, 1996). Since the problem is connected to the threshold relative to TG, the climate of the area will indicate whether one can expect the bias to occur. Previous publications on Crocus performances at Col de Porte (France), obtained in a different snow climate, showed excellent agreement between simulations and field observations. In those cases, gradients were very strong due continental snowpack conditions with shallow snowpacks which never exceeded $1 \mathrm{~m}$ during the winter 1988-89 test (Brun and others, 1992). As a result, the zone of interest highlighted here was not explored.

First, it would be appropriate to re-evaluate the model threshold towards a magnitude neighboring $10^{\circ} \mathrm{C} \mathrm{m}^{-1}$ which would be more in line with typical gradient magnitudes found in the literature (Colbeck, 1982, 1983). It should maintain satisfactory simulation for weak and strong TGs, and prevent underestimation of sphericity for TGs greater than $5^{\circ} \mathrm{C} \mathrm{m}^{-1}$ but still remaining below the $10^{\circ} \mathrm{C} \mathrm{m}^{-1}$ mark. Sechttps://doi.org/10.3189/1998AoG26-1-347-356 Published online by Cambridge University Press ondly, greater sophistication is required. The criteria for faceting depends not only on temperature gradient but also on temperature and pore space (e.g. snow density). Experience shows that for lower temperatures, a higher TG is generally required for facets to develop. Also, density, associated with grain-size and type influences heat conduction and hence temperature. So, metamorphism also depends on density.

\section{Crusts}

Observed and simulated crusts are summarized in Table 1. Simulation reproduced the occurrence and position of crusts.

\section{SURFAGE HOAR}

In Canada, Jamieson and Johnston (1992) have shown that an important proportion of fatal human-triggered slab-avalanche accidents between 1972 and 1991 had failure planes composed of surface hoar in $25 \%$ of the accidents involving non-professional decision-makers and in 50\% involving professional decision makers. This emphasizes the importance of an avalanche-risk assessment system being able to provide information on potential surface-hoar occurrences. In the version of the model tested, no specific scheme was available to simulate the growth of hoar crystals. Growth remains too complex to model and governing parameters are difficult to monitor. Nevertheless, in the surface heat-exchange simulation returned by Crocus there are clues as to the potential for surface hoar to occur. More precisely, the latent-heat exchanges at the surface can retrace the type of 
Table 1. Summary of crusts found in the snowpack ( $F$ : Mount

Fidelity; B: Blackcomb Peak) and the associated simulation

\begin{tabular}{|c|c|c|c|}
\hline Profile date & $\begin{array}{c}\text { Depth of } \\
\text { observed crusts } \\
\mathrm{cm}\end{array}$ & $\begin{array}{l}\text { Depth of } \\
\text { simulated crusts } \\
\mathrm{cm}\end{array}$ & Comments \\
\hline 02-13-94-F & 5 and 10 & 15 & \\
\hline $03-20-94-\mathrm{F}$ & 50 and 60 & $40,50,80$ & \\
\hline $02-08-95-\mathrm{F}$ & 10 & 10 & \\
\hline $02-25-95-\mathrm{F}$ & 40 & 25,70 & $\begin{array}{l}\text { Crust of } 8 \text { February is now } \\
\text { the one simulated at } 70 \mathrm{~cm} \\
\text { below surface }\end{array}$ \\
\hline $03-28-95-\mathrm{B}$ & $\begin{array}{l}40,80, \\
100,180\end{array}$ & $\begin{array}{c}50,80, \\
100,160\end{array}$ & $\begin{array}{l}\text { Simulated crust at } 160 \mathrm{~cm} \text { is } \\
\text { composed of few crust } \\
\text { layers within } 20 \mathrm{~cm}\end{array}$ \\
\hline
\end{tabular}

physical reaction - condensation or evaporation - occurring at a given time (Mingo, 1995). Two main limitations have to be kept in mind. (1) Condensation at the surface does not necessarily imply surface-hoar growth. (2) Available data were obtained by standard weather instruments (except radiometers) not suitable for accurate surface heat-exchange characterization at the micro-scale. However, our approach did enable testing of an analysis scheme based on heat-exchange simulation and weather-parameter analysis as described in this section. Figure $9 \mathrm{a}$ and b show latent heat predicted by Crocus with potential "surface-hoar periods" (SHPs) - marked by semi-horizontal brackets - and observed SHPs (vertical bars). A latent-heat plot barely gives sufficient information to locate a SHP. To improve on this, the first step was to isolate parts of the plot where significant condensation was simulated. Next, meteorological data were combined in the analysis to refine the resolution. When cold air is associated with calm conditions, low cloudiness and fairly high relative humidity, conditions favorable for surface hoar occur (Lang and others, 1984; Breyfogle, 1987). A combined analysis led to the results illustrated in Table 2.

To establish that a derived SHP qualified as an actual growth period, criteria were defined as follows: (1) the SHP had to overlap observation of growth crystals at the surface of the snowpack; or (2) a SHP had to be followed closely by observation of buried surface hoar. Possible destruction of crystals by wind or sun had to be taken into account, still quite qualitatively. The exact timing of the occurrence could not be strictly defined and hence was not studied. Surface-hoar occurrences were only recorded when terrain observations were made and sometimes only recorded once buried. At this stage attempting to correlate simulation and meteorological analysis roughly with field observations was the principal goal pursued.
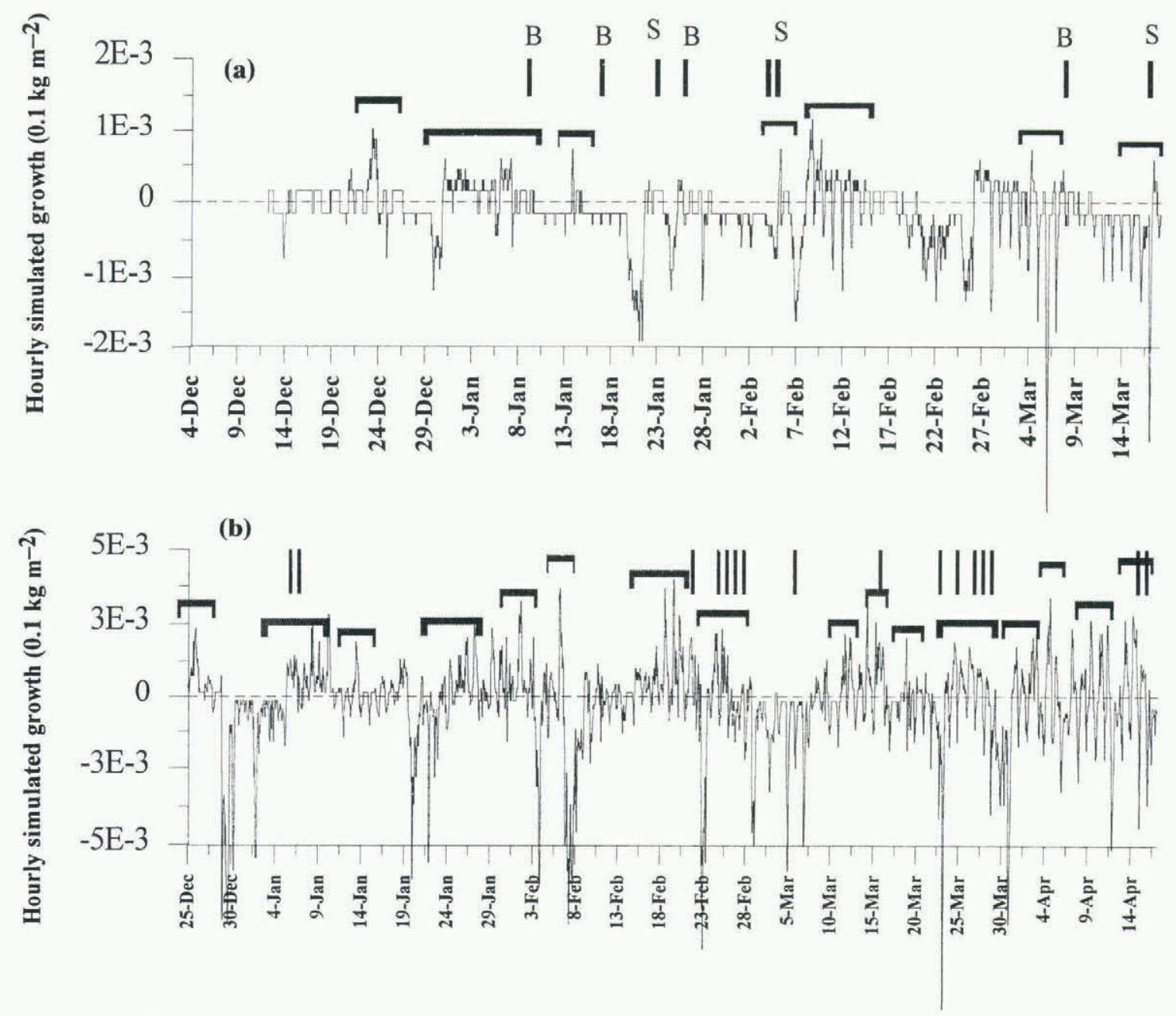

Fig. 9. Simulation of latent heat at the surface of the snow cover. Latent heat is associated with condensation/evaporation at the surface and can be related to surface-hoar growth. Horizontal brackets show surface-hoar periods (SHPs), while vertical lines mark observed surface-hoar occurrence. " $B$ " relates to buried layers of surface hoar and " $S$ " to surface hoar found on the top of the snowpack. (a) Mount Fidelity, winter 1994 95. (b) Blackcomb Peak, winter 1994-95, all occurences observed at the surface. 
Table 2. Contingency table of SHP defined with heat-exchange simulation and meteorological analysis for the Mount Fidelity site (winters 1993-94 and 1994-95) and Blackcomb Peak sites

$\begin{array}{ll}\begin{array}{l}\text { Simulation }+ \text { Analysis } \\ \text { Observation }\end{array} & \text { SHP }\end{array}$

\begin{tabular}{ccc}
\hline SHP & $70.5 \%$ & $6 \%$ \\
No SHP & $23.5 \%$ & - \\
\hline
\end{tabular}

\section{CONCLUSION}

Assessment of Crocus with respect to key parameters of snowcover stability proved to be highly informative. Very good performances were confirmed for snow depth, temperature, density and crust formation. Testing the model under two different climatic zones demonstrated the sensitivity of grain-metamorphism schemes to the type of snow climate the model was applied to.

Unsuccessful simulations were associated with climatic patterns occurring when a given layer was submitted to a TG slightly $>5^{\circ} \mathrm{C} \mathrm{m}^{-1}$ (model's threshold) but still $<10^{\circ} \mathrm{C}$ $\mathrm{m}^{-1}$. A critical zone of erroneous simulations could be expected when TGs were found between $5^{\circ}$ and approximately $9^{\circ} \mathrm{C} \mathrm{m}^{-1}$. On the other hand, successful simulations were associated with both weak (strictly $<5^{\circ} \mathrm{C} \mathrm{m}^{-1}$ ) and strong (superior or equal to $10^{\circ} \mathrm{Cm}^{-1}$ ) TGs. A simple threshold tuning is proposed to fix this problem.

Considering that surface hoar is one of the major types of grain found in the failure planes of fatal avalanche accidents, an innovative appraisal of the model to help predict this type of grain has shown encouraging results. In a more global sense, Crocus remains distinct and valuable as a link between meteorological data and snowpack parameters. Nevertheless, care must still be taken when working with larger model schemes for snowpack-stability evaluation or avalanche-hazard assessment where several numerical models interact with each other. Each individual block brings its own limited "efficiency", so the global system only conserves what is left in terms of usable information. Even a "perfect" snowpack model, returning the same output as Crocus, would not be able to solve the several unknowns (or little known in a deterministic sense) such as hardness or grain bonding which are important for assessing stability. As far as surface hoar is concerned, improvement of surface heat-exchange simulations with possibly better-suited instruments (e.g. infrared thermometers) and progress in the analysis of the direct meteorological data should lead to a reasonable predictive scheme in future.

\section{ACKNOWLEDGEMENTS}

This research was sponsored by the Natural Sciences and Engineering Research Council (NSERC) and the International Council for Canadian Studies (ICCS). We acknowledge their contribution to the project. We are grateful to E. Brun at the Centre d'Études de la Neige for providing us with Crocus and for his advice on running the model. We thank D. Skjönsberg and B. McMahon of Glacier National Park for their help and support to work out all the necessary facilities for the Mount Fidelity site. A very special thanks is due to the avalanche control personnel of Rogers Pass, who helped us in the field throughout this project. We are equally grateful to W. Mark and P. Skelton of Blackcomb Mountain Resort, for giving us access to the site and for making all the necessary arrangements to facilitate our work, as well as the Blackcomb staff for helping us whenever possible.

\section{REFERENCES}

Alados-Arboledas, L., J. Vidas and J. I. Jiminez. 1988. Effect of solar radiation on the performance of pyrgeometers with silicon domes. F. Atmos. Oceanic Technol., 5, $666-670$.

Armstrong, R. L. and B. R. Armstrong. 1987. Snow and avalanche climates of the western United States: a comparison of maritime, intermountain and continental conditions. International Association of Hydrological Sciences Publication 162 (Symposium at Davos 1986-Avalanche Formation, Movement and Effects ), 281-294.

Birkeland, K., R. Johnson and S. Schmidt. 1997. Near surface faceted crystals: conditions necessary for growth and contribution to avalanche formation, southwest Montana, U.S.A. In ISSW'96. International Snow Science Workshop, 6-10 October 1996, Banff, Alberta. Proceedings. Revelstoke, B.C., Canadian Avalanche Association, 75-80.

Breyfogle, S. R. 1987. Growth characteristics of hoarfrost with respect to avalanche occurrence. In ISSW86. International Snow Science Workshop, 22-25 October 1986, Lake Tahoe, California. Proceedings. Homewood, CA, ISSW Workshop Committee, 216-222.

Brun, E. and L. Rey. 1987. Field study on snow mechanical properties with special regard to liquid water content. International Association of Hydrological Sciences Publication 162 (Symposium at Davos 1986 - Avalanche Formation, Movement and Effects ), 183-192.

Brun, E., E. Martin, V. Simon, C. Gendre and C. Coléou. 1989. An energy and mass model of snow cover suitable for operational avalanche forecasting. 7. Glaciol., 35 (121), 333-342.

Brun, E., P. David, M. Sudul and G. Brunot. 1992. A numerical model to simulate snow-cover stratigraphy for operational avalanche forecasting. 7. Glaciol., 38(128), 13-22.

Colbeck, S. C. 1982. Growth of faceted crystals in a snow cover. CRREL Rep. 82-29.

Colbeck, S. C. 1983. Theory of metamorphism of dry snow. J. Geophys. Res., 88 (C9), 5475-5482.

Giraud, G. 1993. MEPRA: an expert system for avalanche risk forecasting. In Armstrong, R., ed. ISSW '92. A Merging of Theory and Practice. International Snow Science Workshop, 4-8 October 1992, Breckenridge, Colorado. Proceedings. Denver, CO, Avalanche Information Center, 97-104.

Jamieson, J. B. and C. D. Johnston. 1992. Snowpack characteristics associated with avalanche accidents. Can. Geotech. 7., 29(5), 862-866.

Lang, R. L., B. R. Leo and R. L. Brown. 1985. Observations on the growth process and strength characteristics of surface hoar. In ISSW84. International Snow Science Workshop, 24-27 October 1984, Aspen, Colorado. Proceedings. Aspen, CO., ISSW Workshop Committee, 188-195.

McClung, D. M. 1995a. Computer assistance in avalanche forecasting. In ISSW'94. International Snow Science Workshop, 30 October - 3 November 1994, Snowbird, Utah. Proceedings. Snowbird, UT, P.O. Box 49, $310-313$.

McClung, D. M. 1995b. The effects of temperature of fracture of dry Alpine snow. In Sivardière, F., ed. Les apports de la recherche scientifique à la sécurité neige, glace et avalanche. Actes de Colloque, Chamonix 30 mai-3 juin 19.95. Grenoble, Association Nationale pour l'Étude de la Neige et des Avalanches (ANENA), 317-322.

McClung, D. M. and P. A. Schaerer. 1993. The avalanche handbook. Seattle, WA, The Mountaineers.

Mingo, L. 1995. Test of the snow cover numerical model CROCUS under a transitional snow climate with regards to operational avalanche forecasting. In Sivardière, F., ed. Les apports de la recherche scientifique à la sécurité neige, glace et avalanche. Actes de Colloque, Chamonix 30 mai-3 juin 1995. Grenoble, Association Nationale pour l'Étude de la Neige et des Avalanches (ANENA), 43-48.

Mingo, L. 1996. Assessment of the snow-cover numerical model CROCUS: application to avalanches and hydrology. (M.A.Sc. thesis, University of British Columbia. Department of Civil Engineering.)

Pahaut, E. 1975. Les cristaux de neige et leurs métamorphoses. Saint-Martind'Hères, Météo-France. Centre d'Études de la Neige. (Monographie de la Météorologie Nationale 96.

Schweizer, J. and P. M. B. Fònn. 1996. Avalanche forecasting - an expert system approach. J. Glaciol., 42(141), 318-332. 